\title{
Differential effects on tonic and phasic reflex mechanisms produced by vibration of muscles in man
}

\author{
P. DE GAIL ${ }^{1}$, J. W. LANCE, AND P. D. NEILSON \\ From the Division of Neurology, Prince Henry Hospital, Sydney, and the School of Medicine, \\ University of New South Wales, Australia
}

There is evidence that transmission of the vibration wave set up by percussion in human subjects is responsible for reflex 'spread' or 'irradiation' (Lance and de Gail, 1965). The afferent pathway for reflex contraction of muscles involved in the irradiated response originates in the muscles concerned, and the latency of such a reflex is consistent with the propagated vibration wave being the adequate stimulus. The inference that muscle spindles are responsive to vibratory stimuli is supported by animal experimentation (Echlin and Fessard, 1938; Granit and Henatsch, 1956; Bianconi and Van der Meulen, 1963).

During the course of investigation of the spread of reflexes, an attempt to initiate phasic reflexes by applying a mechanical vibrator to muscle was unsuccessful, probably because the stimulus was not of sufficient brevity or intensity to produce a synchronous afferent volley. However, two interesting observations were made concerning the effect of more prolonged vibration. Mechanically elicited phasic reflexes (tendon jerks) were found to be depressed while the vibrator was applied to the appropriate muscle, and, in most instances, a gradual involuntary contraction developed in the muscle vibrated. A preliminary report of these findings was presented at the annual meeting of the Australian Association of Neurologists in 1964 (Lance, 1965). It has recently come to our notice that Hagbarth and Eklund have been investigating tonic contraction of muscle evoked by vibration of tendon (Eccles, personal communication) and reported the results to the first Nobel symposium in Stockholm in 1964 (Hagbarth and Eklund, 1965).

The present paper analyses the phenomena of phasic reflex depression and tonic contraction produced by vibration of muscle.

\section{PROCEDURE}

Twenty-three normal subjects were studied by recording the amplitude of tendon jerks in the lower limbs and the 'Merck Sharp and Dohme research fellow. effect of vibration of the quadriceps femoris or triceps surae, or both. Three patients with lumbar disc compression of nerve roots, who had unilateral absence of knee jerk, with normal power and cutaneous sensation, were examined. Two patients with unilateral cerebellar signs, 12 with low cervical or thoracic spinal cord transection, and one with post-anoxic decerebrate rigidity were studied.

Subjects adopted a comfortable sitting or supine position with legs dependent at the knees for experiments on the quadriceps, and lay prone for study of the triceps surae, with the feet projecting over the edge of the table. Force of contraction of the quadriceps was measured by strapping a transducer lightly in front of the ankle joint of the dependent leg, while for the triceps surae, the transducer rested against the sole under the metatarsal heads, lightly restricting the foot so that the ankle was approximately at a right angle. The transducer consisted of a strip of spring steel, bearing a bonded strain gauge supplying a Philips strain bridge, the output of which drove one pen of a curvilinear writing Grass 5D fourchannel polygraph. Paper speed was usually $1 \mathrm{~mm}$./sec. Force measurements were calibrated using known weights. An electromyogram (E.M.G.) during vibration was not always displayed on the polygraph because of artefacts produced by vibration of the electrodes. Muscles were vibrated by one of two devices. One was a lightweight physiotherapy massage machine, and the other a modified portable floor sanding machine. Both were orbital vibrators, having A.C. motors with variable voltage supply. Frequency of vibration was monitored by a piezo-electric phonograph pickup strapped to the skin. Tendon jerks were elicited manually with a rubber-covered reflex hammer, using near-constant force.

The $\mathrm{H}$ reflex during and after vibration of the triceps surae was studied in six normal subjects. Subjects lay prone, and cathodal shocks were delivered to the medial popliteal nerve in the popliteal fossa through a salinesoaked gauze pad electrode. The anode was a 6 in. $\times$ 4 in. sheet of lead applied to the opposite side of the limb, just above the patella. Stimulating shocks, single, paired, or in tetanic trains, were supplied by Grass S4 stimulators through an isolation unit. Stimuli were square waves of $1 \mathrm{msec}$. duration, the voltage being varied to produce an optimal $\mathrm{H}$ reflex.

An electromyogram of the triceps surae was recorded 
through paired surface solder electrodes firmly strapped $10 \mathrm{~cm}$. apart over the centre of the muscle belly, and separated from the stimulating electrode by an earthed lead strip. Electromyogram potentials were led to a Tektronix 122 low level preamplifier, the output of which supplied a monitor oscilloscope and the storage oscilloscope (Tektronix 564). Photographs of the storage oscilloscope screen were taken by a Tektronix C13 oscilloscope camera, using Polaroid-Land film.

\section{RESULTS}

The slowly developing contraction induced by vibration of muscle, referred to henceforth as 'tonic contraction', was found in nearly all normal subjects, with great variations in magnitude. The muscles selected for special study were the quadriceps femoris and triceps surae (gastrocnemius-soleus), but tonic contraction was also seen with vibration of other muscles.

Under the experimental conditions, the force of contraction evoked by vibration of quadriceps ranged from 0.1 to $2.2 \mathrm{~kg}$. and of triceps surae $Z$ from 0.1 to $0.7 \mathrm{~kg}$. There was a wide variation from one subject to another in the force evoked, and also variation in an individual, depending on the site of application. Firm application of the vibrator over the centre of the muscle belly was required to produce a maximal contraction.

In any subject, the force of tonic contraction bore no relation to the briskness of the tendon jerk; indeed tonic contraction occurred in otherwise $\vec{F}$ normal subjects whose tendon jerks were almost absent. Furthermore, depression of tendon jerks by vibration occurred when little or no tonic contraction was evoked (Fig. 1a), even if the vibrator were applied on the opposite side of the limb. Reflexes were not depressed by the pressure of the inactive vibrator, by touch or pinprick to the limb, $\vec{\circ}$ or by application of the active vibrator to the opposite limb.

It therefore appeared that the tonic contraction and the depression of tendon jerks produced by vibration are independent phenomena.
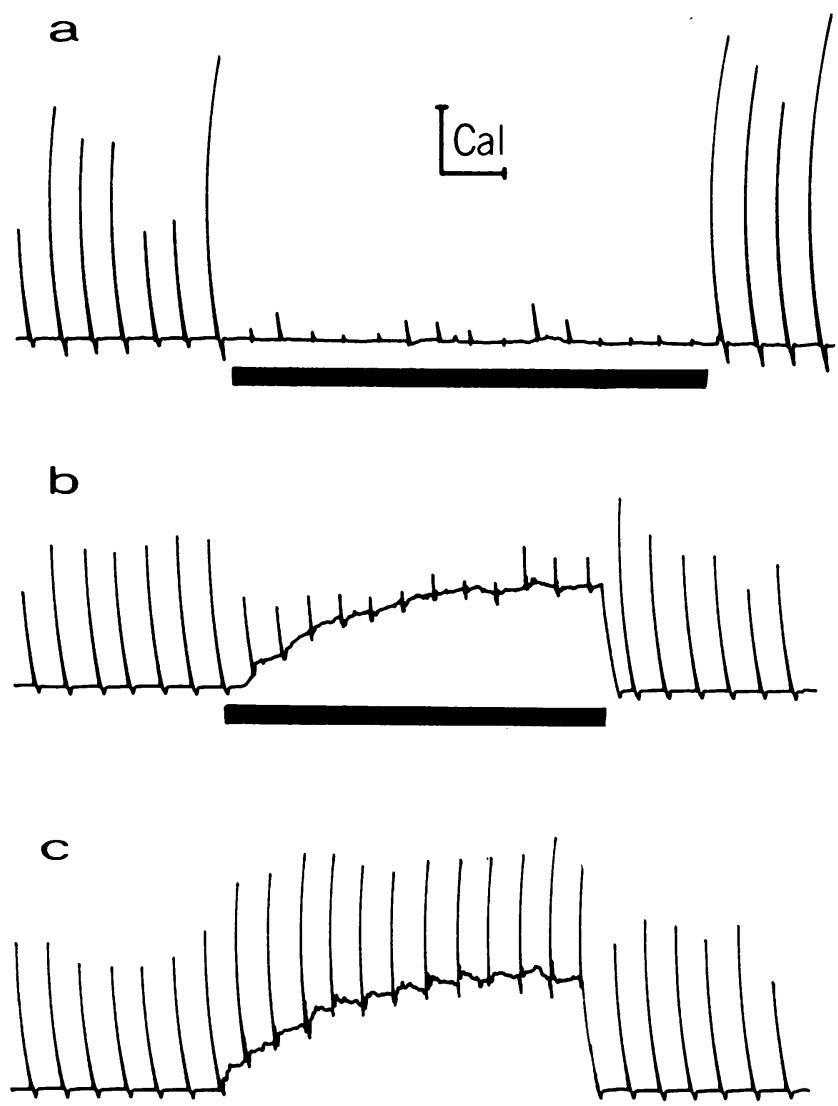

FIG. 1. The effects of vibration compared wite those of voluntary muscle contraction.

a Vibration of quadriceps muscle in norme subject, with patellar tendon jerks elicite regularly at five-second intervals. Marked depression of tendon jerks was observed throughout period of vibration in this subject without development of a tonic contraction.

$b$ Tonic contraction produced by vibration of quadriceps muscle in most normal subjects. Gradual development of contraction, with concomitant depression of knee jerks.

c Voluntary contraction of quadriceps in same subject as in $b$. The knee jerk is not depressed during the period of voluntary contraction.

Solid bar = duration of vibration at $50 / \mathrm{sec}$

Calibration

Vertical $=0.4 \mathrm{~kg}$. for $a$

$0.6 \mathrm{~kg}$. for $b$ and $c$

Horizontal $=10 \mathrm{sec}$. for $a, b$, and $c$ 
TONIC CONTRACTION Tonic contraction usually developed gradually and the force exerted increased to a maximum level after about 30 to 60 seconds (Fig. 1b). Removal of the vibrator caused a rapid decline to baseline levels. Tonic contraction increased progressively as the frequency of vibration was increased up to $50 / \mathrm{sec}$. Above this frequency tonic contraction was variable and the exact frequency difficult to monitor because of the appearance of harmonic waves. Frequencies of $20 / \mathrm{sec}$. and $50 / \mathrm{sec}$. were employed for the experiments described below.

REFLEX NATURE AND PATHWAY Tonic contraction was observed in 19 out of 20 normal subjects, who had not been informed of the existence of the phenomenon. Although the contraction could be stopped at any time by a conscious effort, it reappeared at once if the subject relaxed or permitted his attention to wander (Fig. 2a). Attempts to simulate voluntarily the gradually increasing contraction proved quite difficult, even when the writing pen of the polygraph was being watched carefully by the subject. Such voluntary contractions were not accompanied by the tendon reflex depression associated with vibration-induced tonic contraction (Fig. 1c). Tonic contraction was not observed when the vibrator was applied to bone, joints, neighbouring muscles, or when light contact was made with the skin overlying the muscle concerned, but could be seen if the tendon were vibrated.

Three patients with nerve root compression from lumbar disc disease, who had complete absence of the patellar tendon jerk on one side, without quadriceps weakness or wasting, and without cutaneous sensory impairment, were studied. Application of vibration to the quadriceps on the unaffected side elicited a tonic contraction, but there was no tonic contraction on the areflexic side.

Twelve patients with signs of spinal cord transection below the sixth cervical segmental level were studied. Power and tendon jerks were preserved in the biceps brachii of each patient, and a tonic contraction could be elicited by the application of vibration to the muscle bellies or tendons. Knee jerks were brisk in the paralysed lower limbs, but tonic contraction could not be elicited from the quadriceps in 11 out of the 12 patients. However depression of knee jerks during vibration was evident in all 12 patients.

Another patient, with post-anoxic decerebrate rigidity, had extended, pronated arms, and extended legs with plantar flexion of feet, the plantar reflexes being extensor. Tendon jerks were slightly exaggerated. Vibration of quadriceps muscle elicited no tonic contraction, but caused depression of knee jerks, as in the patients with spinal cord lesions.

Two patients with predominantly unilateral signs

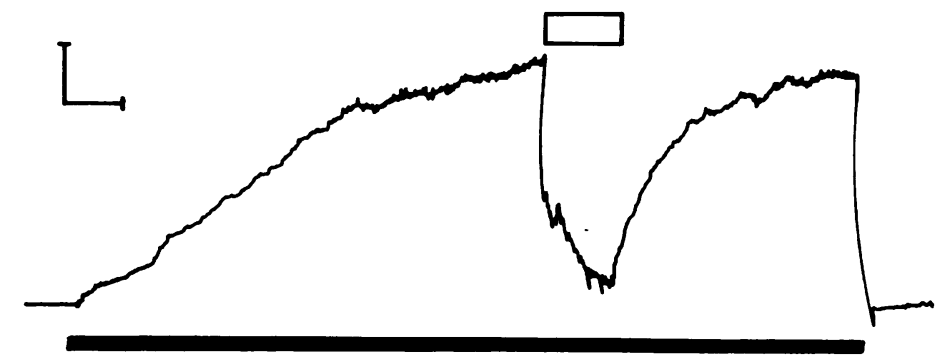

a

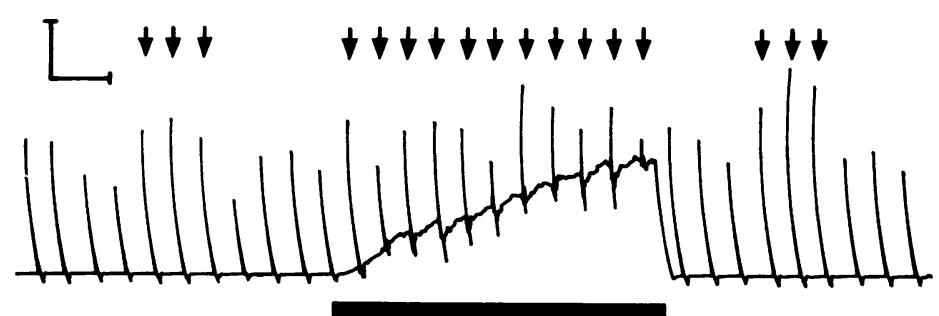

FIG. 2. The effects of relaxation and reinforcement during tonic contraction.

a Tonic contraction resulting from vibration of quadriceps in normal subject. Open bar shows period during which subject was asked to relax the quadriceps. On cessation of effort, the tonic contraction returned rapidly to previous level.

b Tonic contraction with regular elicitation of knee jerks. Arrows mark knee jerks which were preceded by voluntary reinforcement (Jendrassik manoeuvre). Reinforcement during vibration overcame the depression of reflexes.

Solid bar $=$ duration of vibration at 50/sec.

Calibration

Vertical $=0.4 \mathrm{~kg}$. for a $0.6 \mathrm{~kg}$. for $b$

Horizontal $=10 \mathrm{sec}$. for $a$ and $b$ 
of cerebellar deficit exhibited a reduction of tonic contraction on the affected side. One of these patients, in whom a unilateral cerebellar angioma had been demonstrated by vertebral angiography, showed a complete lack of tonic contraction on the ipsilateral side, contrasting with a normal reaction on the unaffected side.

These observations implied that the tonic contraction produced by vibration was mediated by the stretch reflex arc, but was not dependent solely on spinal cord segmental mechanisms.

Procaine block In four subjects, the tonic contraction with vibration, and the force of the tendon jerk, were measured before, and at intervals after, wide infiltration of the quadriceps muscle with 20 to $40 \mathrm{ml}$. of $1 \%$ procaine. Voluntary power was unimpaired and tendon jerks were reduced to about half of the control amplitude while tonic contraction decreased to one third or less of the control level. Since procaine, used in this fashion, is considered to cause a relatively selective block of gamma efferent fibres, this experiment supports the view that the tonic contraction depends upon excitation of the muscle spindles.

Effect of barbiturate Since barbiturates are known to block polysynaptic pathways, the effect of sodium thiopentone on vibration-induced tonic contraction was studied in a normal subject. The vibrator was applied to quadriceps muscle while patellar tendon jerks were elicited regularly at five-second intervals. Forty-five seconds after the onset of vibration, at the height of tonic contraction, a slow intravenous injection of sodium thiopentone was started, and was continued at the rate of $5 \mathrm{mg}$. per second to a total of $400 \mathrm{mg}$. Simultaneously, the superficial abdominal reflexes were elicited at regular intervals.

The result of the experiment is shown in Figure 3. After $225 \mathrm{mg}$. of barbiturate had been injected the tonic contraction began to decrease concurrently with diminution of the abdominal reflexes. When $325 \mathrm{mg}$. had been administered, the tonic contraction ceased altogether, and the abdominal reflexes were completely absent. The tendon jerks were unaffected.

Since the monosynaptic tendon jerk was preserved and tonic contraction was abolished at the same time as superficial abdominal reflexes, which are known to have polysynaptic pathways, this experiment indicates that the tonic contraction reflex involves one or more interneurones.

Effect of Ciba 28,882-Ba The triazine compound Ciba $28,882-\mathrm{Ba}$ is known to have powerful in- iु hibitory effects on polysynaptic reflex transmission $\rightarrow-$ on the sensitivity of static stretch receptors ow muscle spindles, and on the discharge frequency of $\frac{1}{3}$ gamma motor neurones (Bein and Fehr, 1962) These effects were described in anaesthetized and i⿱ $)$ decerebrate cats, the dosage of Ciba 28,882-B being 0.1 to $0.3 \mathrm{mg}$. $/ \mathrm{kg}$. The drug has little or ng

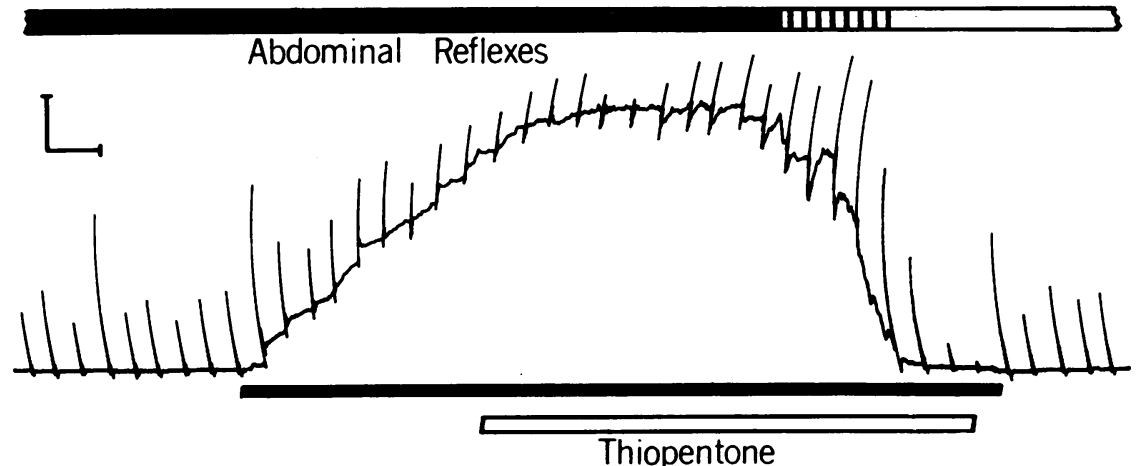

FIG. 3. Effect of sodium thiopentone

Tonic contraction produced by vibration of quadriceps in normal subject. Tendon jerks elicited at five-second intervals, and abdominal reflexes tested repeatedly. Open bar shows intravenous injection of sodium thiopentone at 5 mg. per sec. to total of $400 \mathrm{mg}$. Tonic contraction decreased as abdominal reflexes diminished, and both completely disappeared after injection of $325 \mathrm{mg}$. , while tendon jerks were unaffected.

Solid bar $=$ duration of vibration at $50 / \mathrm{sec}$.

Calibration Vertical $0.4 \mathrm{~kg}$.

Horizontal $=10 \mathrm{sec}$.

Abdominal reflexes Black = normally brisk

Shaded diminished

White = absent 
effect on dynamic stretch receptors of muscle spindles or on monosynaptic reflex transmission.

The effects of this substance on vibration-induced tonic contraction were investigated in three normal subjects, two doses of $1 \mathrm{mg}$. being given intravenously at short intervals. Mild vertigo, nystagmus, and a sensation of warmth occurred in all subjects. In one subject, the experiment was repeated using a single dose of $2 \mathrm{mg}$. intravenously. Nausea, bradycardia, and sweating were noted in addition to vertigo and nystagmus.

In all subjects, the tonic contraction was markedly reduced at the same time as the superficial abdominal reflexes, while tendon jerks were virtually unchanged. Depression of tendon jerks by vibration was unaltered by administration of the drug. These changes were most pronounced when a single dose of $2 \mathrm{mg}$. was given, and are illustrated graphically in Figure 4.

While the slight drop in tendon jerk amplitude during the peak effect of Ciba 28,882-Ba (Fig. 4) might imply some reduction of gamma efferent discharge, the complete and simultaneous abolition of tonic contraction and abdominal reflexes points to polysynaptic blockade as the principal mechanism.

Tonic contraction produced by tetanic stimulation of the medial popliteal nerve Since it appeared that the tonic contraction was mediated reflexly by afferents from muscle spindles, it was postulated that tetanic stimulation of the appropriate nerve might provide an afferent discharge comparable with that induced by vibration.

The $\mathrm{H}$ reflex was elicited in subjects lying prone, stimulus strength being adjusted to yield a submaximal $\mathrm{H}$ reflex without any direct muscle (M) response (Fig. 5a). After several $\mathrm{H}$ reflexes had been recorded as controls at five-second intervals, the nerve was stimulated repetitively at $50 / \mathrm{sec}$. for $60 \mathrm{sec}$. at the same stimulus strength. During the 60 seconds of tetanus, the E.M.G. of triceps surae was monitored continuously on an oscilloscope, a representative $50 \mathrm{msec}$. sweep being shown in Figure 5b. It can be seen that there is no trace of any synchronous electromyographic activity between the stimulus artifacts. Even when the amplification of the E.M.G. was increased tenfold, there was no evidence of either $\mathbf{H}$ or $\mathbf{M}$ responses during tetanic stimulation, but asynchronous potentials of small amplitude, representing the interference pattern of contracting muscle, were observed.

A tonic contraction appeared during tetanic stimulation, and, immediately after cessation of stimulation, the triceps surae relaxed (Fig. 5c). For comparison, the tonic contraction elicited by vibration at $50 / \mathrm{sec}$. in the same subject is shown in Figure 5d.

As a single shock to the muscle nerve at this

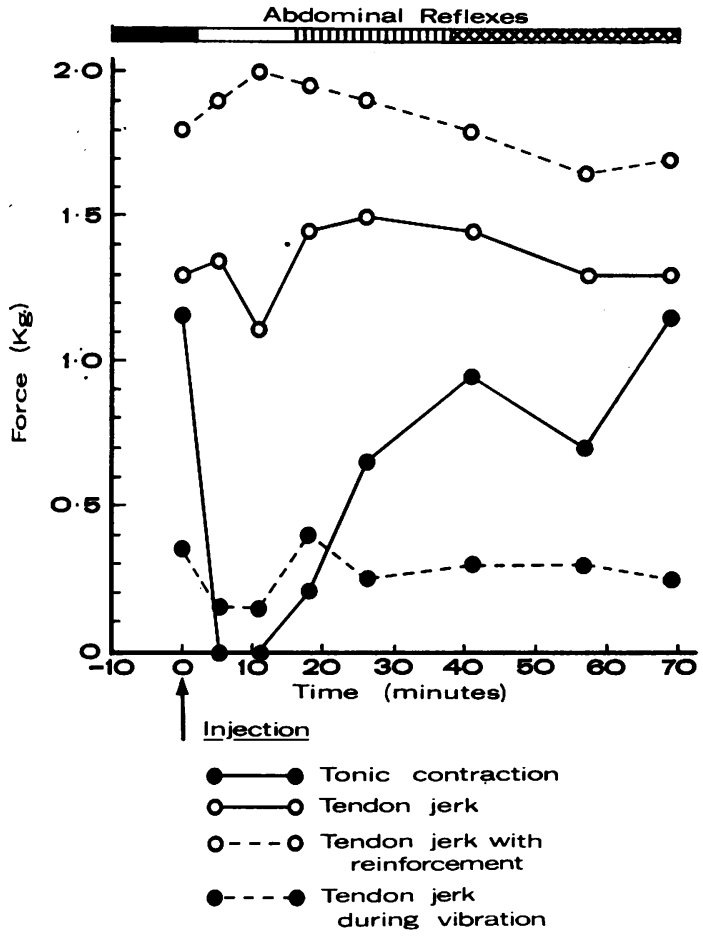

FIG. 4. Effect of Ciba 28,882-Ba.

Observations were made, before and after the intravenous injection of Ciba 28,882-Ba, on the following:-

Tonic contraction attained after one minute of quadriceps vibration at $50 / \mathrm{sec}$.

Average amplitude of knee jerks between, and during, periods of vibration.

Average amplitude of reinforced knee jerks between periods of vibration.

Superficial abdominal reflexes.

Tonic contraction and abdominal reflexes were abolished with little change in amplitude of knee jerk recorded between periods of vibration. Depression of knee jerks during vibration continued unaltered, and reinforcement remained effective throughout. Tonic contraction and abdominal reflexes recovered together.

Abscissa = time in minutes

Ordinate $=$ force of contraction of quadriceps in $\mathrm{kg}$.

Abdominal reflexes Black = normally brisk

White = absent

Vertical bars $=$ markedly reduced

Cross hatch $=$ slightly reduced

stimulus strength elicited an $\mathbf{H}$ reflex, without any $\mathbf{M}$ response, it is probable that only group I afferent fibres were excited. Moreover, during tetanic stimulation there was no electromyographic evidence of any synchronous muscle action potential. Therefore, the slowly developing tonic contraction during tetanic stimulation at $50 / \mathrm{sec}$. cannot be explained by 

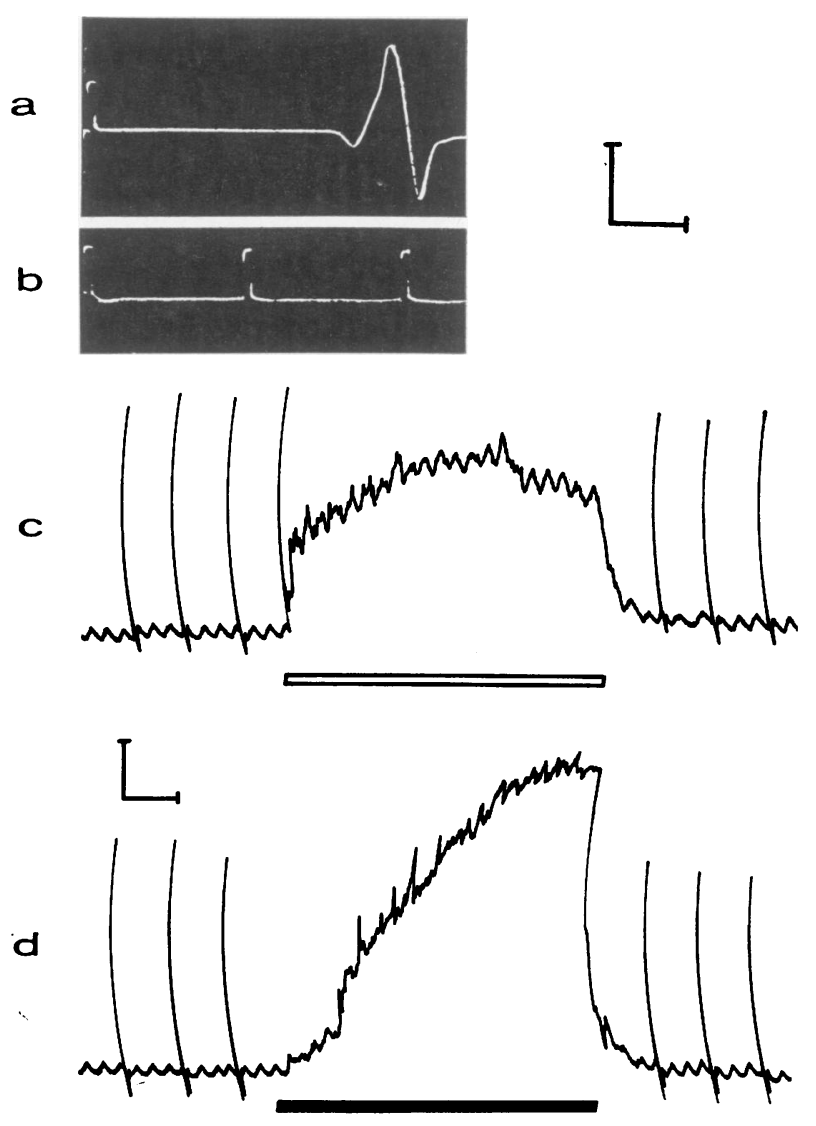

FIG. 5. Tetanic stimulation of medial popli $-\frac{\bar{T}}{2}$ teal nerve.

a Electromyograph of $H$ reflex elicited by single submaximal shock. No $M$ response following stimulus artifact.

b Random 50 msec. oscilloscope sweepก during tetanic stimulation at same $\frac{\overline{\mathrm{N}}}{\text {. }}$ stimulus strength as in a. No synchronous E.M.G. potentials between stimulus artifacts.

c Force of tonic contraction of triceps surae during tetanus. Control $H$ reflexess before and after tetanus.

$d$ Force of tonic contraction of triceps surae during muscle vibration in same⿻ి subject. Ankle jerks elicited by percus-n sion of tendo Achillis superimposed. Ankle jerks were depressed during vibra- $\overrightarrow{0}$ tion and returned to control level after cessation of vibration.

Undulations of the base-line represent respiratory movements.

Open bar = tetanic stimulation of medial popliteal nerve at $50 / \mathrm{sec}$.

Solid bar $=$ vibration of triceps surae.muscle belly at 50/sec.

Calibration of $a$ and $b$ (top right)

Horizontal $=5 \mathrm{mV}$.

Vertical $=10 \mathrm{msec}$.

Calibration of $c$ and $d$ (left, below cents

Vertical $=0.15 \mathrm{~kg}$.

Horizontal $=10 \mathrm{sec}$.

direct efferent fibre stimulation, or by summation of monosynaptic reflex contractions. It seems probable that the afferent impulses produced by tetanic stimulation act in the same way as the muscle spindle discharges during muscle vibration to elicit a reflex tonic contraction.

DEPRESSION OF PHASIC REFLEXES BY VIBRATION OF MUSCLE Tendon jerks were depressed even when tonic contraction was not elicited (Fig. 1a), and no comparable depression was observed during voluntary contraction of the same force as tonic contraction (Fig. 1c). These observations indicate that tendon jerk depression is not due merely to fewer motor neurones being available for participation in the monosynaptic reflex during tonic contraction. Increase in the frequency of vibration above $20 / \mathrm{sec}$. did not appear to be more effective in depression of tendon jerks. Indeed, in some subjects, the effect appeared to diminish with higher frequencies. The tendon jerk was sometimes depressed to less than $5 \%$ of the control level within seconds of the onset of vibration (Fig. 1a), whereas at other times, depression did not reach a maximum for severalo minutes.

Reflex pathways Twelve patients with cervical or thoracic spinal cord transection exhibited depression $\overrightarrow{\vec{B}}$ of knee jerks during vibration of the quadriceps, 3 even though no tonic contraction ensued in 11 out of the 12. In normal subjects, tendon jerk depression? could be overcome at least partly by voluntary reinforcement (Jendrassik manoeuvre) as shown in Figure $2 b$. The depression is therefore mediated at $a_{\circ}-$ spinal cord level, although supraspinal influences 3 . can modify the effect of vibration.

$H$ reflex depression Since the $\mathrm{H}$ reflex is the electrical equivalent of the ankle jerk, it was elicited during vibration of the triceps surae in order to study monosynaptic excitability. Impact of the vibrator on the skin overlying the muscle triggered both the storage oscilloscope sweep and, through a N varied delay, the stimulus to the medial popliteal $N$ nerve.

Providing that no jar was produced by the applica- 
tion of the vibrator, depression of the $H$ reflex started 40 to $100 \mathrm{msec}$. after contact and increased thereafter, the time course varying with each individual. In one subject, the test response was abolished after $100 \mathrm{msec}$. of vibration, while in another the response was still $10 \%$ of the control amplitude after 20 seconds. Onset of depression was more rapid with forceful than with gentle application of the vibrator. If the inactive vibrator were applied sharply, depression occurred initially, but did not persist.

When the procedure was repeated employing a sharp tap on the muscle belly with a reflex hammer instead of the vibrator, depression of the $\mathbf{H}$ reflex was apparent as early as $10 \mathrm{msec}$. after impact, the test response then being reduced to 50 to $60 \%$ of control levels, and was complete in some subjects 50 to $100 \mathrm{msec}$. later. Complete recovery of the $\mathrm{H}$ reflex required up to four to five seconds when the percussion was vigorous.

This experiment demonstrates two components of monosynaptic reflex depression. First there is a variable phase, depending on the force of impact or 'jar', not persisting longer than four to five seconds. Secondly, continued vibration causes depression which persists until the vibrator is removed and which may be slowly cumulative.

Monosynaptic recovery after vibration The recovery of test $\mathrm{H}$ reflexes was followed after five seconds of vibration of the triceps surae (at 20/sec. and $50 / \mathrm{sec}$.), this period being sufficient for the effects of the initial impact to have disappeared. The test shock stimulus to the medial popliteal nerve was approximately 1.2 times liminal strength, eliciting an $\mathrm{H}$ reflex but no $\mathrm{M}$ response. Results from experiments on three normal subjects are depicted graphically (Fig. 6). Recovery of the $\mathrm{H}$ reflex after a five-second conditioning tetanus and after a single conditioning $\mathrm{H}$ reflex elicited at the same stimulus strength as the test response is plotted for comparison.

Post-vibration monosynaptic recovery followed the same time course as recovery after tetanus or after a single conditioning $\mathbf{H}$ reflex, making allowance for individual variations, and was virtually complete after five seconds. In two subjects, depression was more profound after a tetanus at $20 / \mathrm{sec}$. than at 50/sec. (Figs. 6a and 6b). There was very little post-tetanic depression at either frequency in the third subject (Fig. 6c). This subject was also unusual in that miniature $\mathrm{H}$ reflex potentials were recorded even during tetanic stimulation at $100 / \mathrm{sec}$., whereas in other normal subjects a frequency of $50 / \mathrm{sec}$. abolished the reflex response to individual shocks. Post-tetanic potentiation was not observed in any subject at frequencies of $20 / \mathrm{sec}$. and $50 / \mathrm{sec}$. although effects of near liminal or subliminal strength tetanic stimulation were not studied.

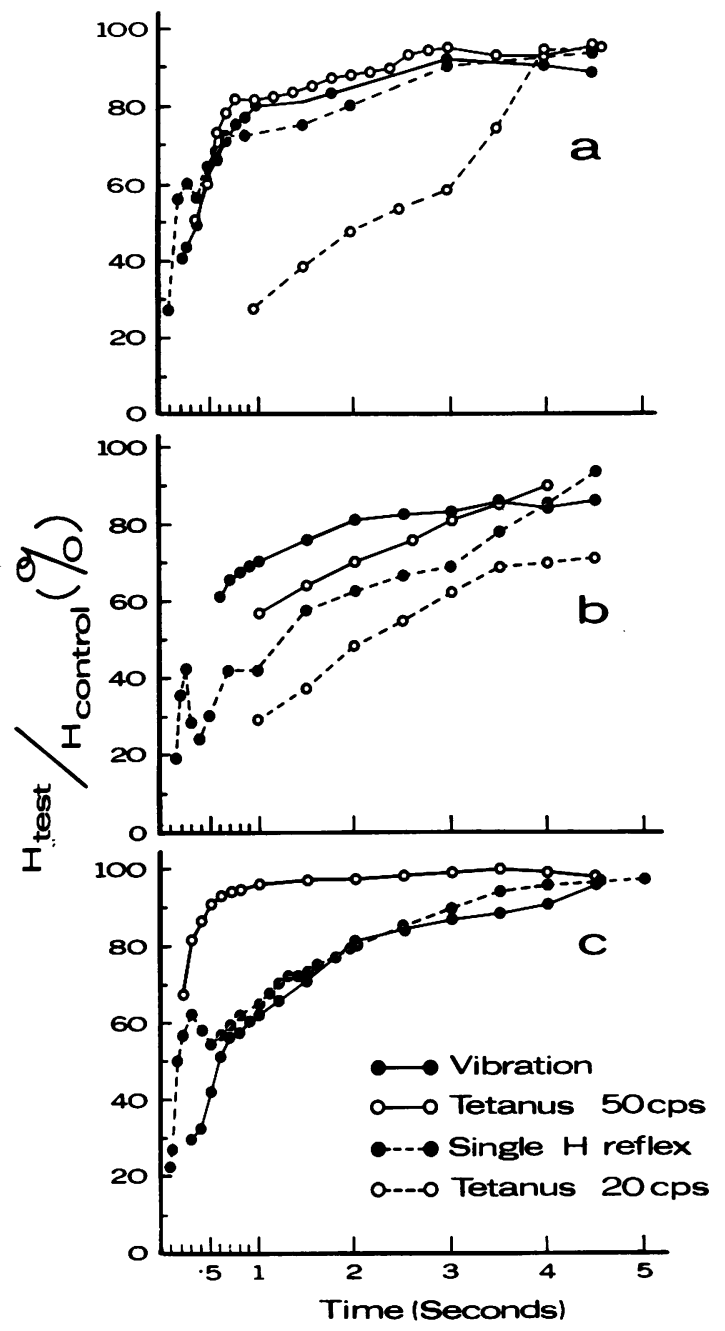

FIG. 6. $H$ reflex recovery in three normal subjects. Amplitude of test $H$ reflex E.M.G. potentials were measured at intervals, and compared with control levels, after the following conditioning stimuli:-

$A$ single conditioning $H$ reflex

Vibration of triceps surae for 5 seconds (at 20/sec. and 50/sec.)

Tetanic stimulation of medial popliteal nerve for 5 seconds (at 20/sec. and 50/sec.)

Stimulus strength, for single shocks and for tetanic trains, was always $1 \cdot 2$ times threshold for $H$ reflex elicitation. Recovery after tetanus at 20/sec. plotted separately for two subjects $(a$ and $b)$, but averaged with that following $50 / \mathrm{sec}$. tetanus in subject c. Post-vibration recovery for the two frequencies (20/sec. and 50/sec.) plotted as one line in all subjects.

All recovery curves represent average results from repeated observations.

Abscissa = time in seconds after single shock, end of vibration, or end of tetanus. 
Since there was no $M$ response at the stimulus intensity used, group I muscle afferents were stimulated almost exclusively. It appears probable that monosynaptic depression caused by vibration of the muscle, and that produced by conditioning tetani at comparable frequencies, employ a similar mechanism, dependent upon group I afferent discharge.

\section{DISCUSSION}

The experimental evidence presented in this paper has led to formulation of an hypothesis to account for the tonic contraction and tendon reflex depression caused by vibration of muscle. It is suggested that vibration excites primary or dynamic stretchsensitive receptors of muscle spindles, resulting in repetitive trains of group 1a afferent impulses at a frequency corresponding with that of vibration, and that such afferent discharge produces two effects within the central nervous system.

One effect is depression of excitability of homonymous alpha motor neurones concerned with phasic monosynaptic reflexes. The second effect is activation of a polysynaptic pathway terminating on tonic alpha motor neurones. Such a polysynaptic pathway must either traverse supraspinal centres such as the cerebellum, or involve spinal segmental internuncial pools which are controlled by supraspinal centres, since the response was diminished on the side of a unilateral cerebellar lesion and was absent below the level of spinal cord transection in 11 out of 12 patients.

It is known that the central regions of nuclear bag intrafusal fibres, containing primary receptors supplied by fast conducting group la afferent nerve fibres, are responsible for the high dynamic sensitivity of muscle spindles and hence for their responsiveness to vibration (Bianconi and Van der Meulen, 1963; Matthews, 1964). The myotube regions of nuclear bag fibres and also the nuclear chain intrafusal fibres are equipped predominantly with secondary receptors, supplied by group II afferent nerve fibres. These are static stretch receptors with much less dynamic sensitivity than primary endings (Cooper, 1961, 1962; Bessou and Laporte, 1962; Matthews, 1963). Muscle spindles respond to a deformation of as little as $8 \mu$ in the frog (Jahn, 1963) and in the decerebrate cat (Denny-Brown and Liddell, 1927), while a stretch of $100 \mu$ is well above that needed for activation of /all group 1a afferents in spinal cats (Lundberg and Winsbury, 1960). Echlin and Fessard (1938) showed that spindle afferent discharge from vibrated muscle is composed of rhythmic series of waves synchronized with the rate of vibration. Although velocity rather than amplitude of stretch is probably the critical factor, it $\frac{\text { O }}{Z}$ could be anticipated that vibration of muscle bellies, $\mathbb{\mathbb { Q }}$ as in our experiments, would impart sufficient movement to spindles to stimulate dynamic receptors. It seems unlikely that Golgi tendon organs couldo be excited by vibration since they are high threshold ${ }_{\infty}^{D}$ tension receptors in series with extrafusal muscle fibres.

Procaine affects small nerve fibres more than $\stackrel{乛}{5}$ large, and hence blocks gamma efferents before large afferent fibres (Matthews and Rushworth, 1957a, b), although Gassel and Diamantopoulos(1964) have shown that some large diameter afferents are blocked as well. In any event, the reduction of $\frac{\overline{\bar{c}}}{\overline{2}}$ amplitude of tonic contraction by procaine infiltra- $\vec{\otimes}$ tion of the muscle belly is in favour of the origin of the afferent impulses responsible for it being in the ${ }^{\infty}$ muscle spindle, since muscle power was unaffected. $\stackrel{\circ}{\circ}$ The reflex nature of tonic contraction is confirmed $\vec{\overrightarrow{ }}$ by its absence when the tendon jerk of the appro- $\omega$ priate muscle had been abolished by compression of $\overline{\bar{T}}$ the spinal nerve root without impairment of muscle power. Vibration-induced tonic contraction can be simulated closely by tetanic stimulation of group afferent fibres. Considering all the foregoing point $\overline{\vec{S}} \overrightarrow{-}$ it seems reasonable to conclude that vibration of muscle in the human subject activates prima spindle endings to cause repetitive group la afferege $T^{\top}$ volleys, which then produce reflex events in the 을 central nervous system.

The reflex effects of muscle vibration in humat subjects are clearly different for tonic and phaste $\vec{\theta}$ mechanisms. The motor neurone population supplying the vibrated muscle shows enhanced activity in the production of tonic contraction while responding less readily to synchronous stimuli, as reflected in depression of tendon jerks. That the impairment of tendon jerks is not simply due to the vibratory $\mathbb{D}$ stimulus engaging the muscle spindles and thereby rendering them insensitive to sudden stretch is shown by the simultaneous depression of $\mathrm{H}$ reflexes, which do not depend upon spindle activity. Moreover, the reduction in tendon jerks is not the result of occlusion in the anterior horn of spinal cord, since it may be observed in the absence of tonic contraction, and is not apparent with a voluntary contraction of the same force as reflex tonic contraction. It is therefore necessary to postulate the presence of both tonic and phasic anterior horn cells in man, which are affected in opposite manner by group 1a afferent volleys.

Separate tonic and phasic motor neurones in the gastrocnemius-soleus muscle have been demonstrated in the cat (Granit, Henatsch, and Steg, 1956). Tonic motor neurones responded to stretch by repetitive firing when potentiated by preceding 
afferent tetani at $500 / \mathrm{sec}$, for 10 seconds, whereas phasic motor neurones continued to show only single discharges when stretched following tetanization. Tonic motor neurones have smaller ventral root spikes than phasic, and react characteristically to repeated stretch and electrical tetanization by residual facilitation or post-tetanic potentiation (Granit, Phillips, Skoglund, and Steg, 1957). Moreover, tonic motor neurones supply slowcontracting red muscle fibres, and have a prolonged after-hyperpolarization, in excess of $130 \mathrm{msec}$., whereas phasic motor neurones supply fast-contracting pale muscle fibres and have an after-hyperpolarization of 50 to $110 \mathrm{msec}$. (Eccles, Eccles, and Lundberg, 1958).

It is apparent that tonic contraction and phasic reflex depression must employ different central pathways, apart from their expression through separate types of motor neurone. Tonic contraction is diminished or abolished by sodium thiopentone and Ciba $28,882-\mathrm{Ba}$, and it is of interest that both drugs produce symptoms and signs of cerebellar dysfunction as well as blocking polysynaptic pathways generally. Since tonic contraction is diminished or abolished on the side of a unilateral cerebellar lesion, and since group la afferent fibres are known to have a massive projection to the cerebellum, it is possible that the reflex is normally mediated through the cerebellum.

The cerebellum exerts profound influences on spinal motor systems. Henatsch, Manni, Wilson, and Dow (1964) observed widespread, predominantly facilitatory effects on gamma tone of hind limb extensors of decerebrate cats when deep cerebellar structures were stimulated. Tonic properties of alpha motor neurones were also facilitated or inhibited directly. Although considerable independence exists between cerebellar gamma and alpha effects, the amount of gamma support determines the threshold of alpha effects (Henatsch, Manni, and Dow, 1964). It was previously shown by Granit and Henatsch (1956) that the muscle spindle, when in a state of tension from gamma bias, responds to a considerably faster rate and lower amplitude of vibration than in the slack state. It would therefore be possible for group Ia afferent fibres, activated by vibration of the spindle, to produce reflex effects on both gamma and alpha motor neurones through the cerebellum. The resulting gamma bias, by rendering the spindle more susceptible to the effect of vibration, could lead to a progressive enhancement of the reflex action on tonic alpha motor neurones and thus give rise to a progressively augmenting tonic contraction.

In contrast to tonic contraction, the depression of tendon jerks by muscle vibration takes place below the level of spinal cord transection. It de- pends, therefore, upon spinal mechanisms but can be influenced from supraspinal levels in that reinforcement by the Jendrassik manoeuvre will overcome it, at least partly.

The recovery of $\mathbf{H}$ reflexes after a single conditioning $\mathrm{H}$ reflex and after a tetanus has been compared with recovery after vibration. We have not observed post-tetanic potentiation of $\mathbf{H}$ reflexes with the parameters of stimulation employed. Hagbarth (1962) and Corrie and Hardin (1964) found posttetanic potentiation in human subjects after conditioning tetani of 100 to $500 / \mathrm{sec}$. for 10 to 60 seconds, and $300 / \mathrm{sec}$. for 20 seconds, respectively. We have used trains of 20 to $50 / \mathrm{sec}$. for five seconds in an attempt to produce afferent stimulation comparable with that evoked by vibration at the same frequency. Test $\mathbf{H}$ reflexes were depressed after both tetanus and vibration, the recovery curve being similar in time course after each. We have employed a stimulus voltage approximately $1 \cdot 2$ times that necessary to produce a liminal $\mathrm{H}$ response. Since the threshold for electrical stimulation of group II afferent fibres is 1.3 to 1.5 times group I threshold (Eccles and Rall, 1951), it is unlikely that group II inhibitory effects could be responsible for the post-tetanic depression described here. Moreover, vibration has relatively little effect in initiating impulses in group II afferent fibres from spindle secondary endings (Bianconi and Van der Meulen, 1963), and yet depression after vibration was comparable with that after tetanus. It therefore becomes necessary to consider mechanisms by which repetitive activation of group Ia fibres alone can produce depression of monosynaptic activity.

Depression of monosynaptic excitability of phasic motor neurones could be explained by the reduction of excitatory post-synaptic potentials (E.P.S.P.s) by low frequency tetanization, providing that vibration produced synchronous volleys in the manner of electrical stimulation. Curtis and Eccles (1960) showed that at frequencies of group Ia stimulation between $1 / \mathrm{sec}$. and $50 / \mathrm{sec}$., the steady state excitatory post-synaptic potential of the cat motor neurone was depressed, the lowest level being $85 \%$ of the resting excitatory post-synaptic potential. The same authors also demonstrated that the frequency of tetanic stimulation affected the post-tetanic excitatory post-synaptic potential, there being depression following brief tetani at $100 / \mathrm{sec}$., but potentiation after higher frequencies. Eccles (1964a) states that 'these potentiations or depressions of the excitatory post-synaptic potential after brief conditioning tetani correspond to the post-tetanic potentiations or depressions of mono-synaptic reflexes under comparable conditions'. However, it seems unlikely that vibration could induce afferent 
volleys so synchronous as to cause a depression of excitatory post-synaptic potentials throughout the whole motor neurone pool, to produce such a profound effect as we have observed. Pre-synaptic inhibition is unlikely to be responsible for monosynaptic depression by vibration, because afferent volleys from group 1a fibres originating in extensor muscle spindles have little or no inhibitory effect on neighbouring group 1a fibres in the spinal cord (Eccles, 1964b).

In view of the gradual reduction of tendon jerks observed in some subjects, increasing steadily over a period of seconds or even minutes after the onset of vibration, it is possible that a pool of internuncial neurones may participate in a process of inhibition. However, depression of knee jerks by vibration persisted at the height of activity of Ciba $28,882-\mathrm{Ba}$, when tonic contraction was abolished, a point against the involvement of inhibitory interneurones. Languth, Teasdall, and Magladery (1952) have shown that the phase of secondary depression in the $\mathbf{H}$ reflex recovery cycle is abolished by a spinal cord lesion situated a few segments rostral to that concerned with the monosynaptic reflex being studied. Intense rigidity of the limbs of the alpha type may be produced by a spinal cord lesion which isolates anterior horn cells from inhibitory influences (Rushworth, Lishman, Hughes, and Oppenheimer, 1961). Murayama and Smith (1965) have recently reported the production of permanent hind limb rigidity in cats by temporary ischaemia of the lumbar spinal cord. In these cats, muscle spindle receptors, intrafusal muscle fibres, and fusimotor neurones did not exhibit grossly abnormal behaviour, but polysynaptic reflex responses were decreased or absent. The authors postulated that destruction of internuncial neurones was responsible for the rigidity. Whatever the nature of the tendon jerk depression by vibration, it is probable that the mechanism is similar to the depression of $\mathrm{H}$ reflexes following a single group 1a afferent shock or a tetanic train, since the recovery period is comparable.

The demonstration of separate tonic and phasic mechanisms in man is of great interest, and may be of importance in explaining the paradoxical dichotomy between muscle 'tone' and tendon jerks observed in certain clinical states, e.g., the brisk pendular reflexes seen so often in patients with cerebellar hypotonia. The differential reflex effects of muscle vibration on these two mechanisms may prove a useful tool in the elucidation of disorders of the motor system.

SUMMARY

Differential effects on tonic and phasic spinal reflex mechanisms have been produced by vibration of muscle in human subjects. Phasic reflexes (tendon jerks and the $\mathrm{H}$ reflex) were depressed while, in mos\$ subjects, a tonic contraction slowly developed it the muscle vibrated.

Tonic contraction was diminished by procaine infiltration of the muscle belly. It was absent on the्e areflexic side in patients with unilateral nerve roof compression, and bilaterally below the level of spina: cord lesions. It was diminished or absent on the side affected by unilateral cerebellar lesions in two patients. Tonic contraction was abolished by the intravenous injection of thiopentone and $\mathrm{Cib}$ $28,882-\mathrm{Ba}$. Tonic contraction of the triceps suras was produced by tetanic stimulation of the mediats popliteal nerve in the absence of $\mathrm{H}$ or $\mathrm{M}$ responses. It was concluded that vibration excited muscles spindles to produce repetitive group 1a afferene volleys which induce tonic contraction by a poly $\overrightarrow{0}$ synaptic pathway terminating upon tonic motor neurones. The reflex depends upon supraspinas centres, possibly the cerebellum.

Depression of tendon jerks and the $\mathrm{H}$ reflex was produced by vibration of the appropriate musclen whether or not a tonic contraction developed. Reinforcement partly overcame this depression:No depression was observed during voluntary con? traction. Depression of tendon jerks occurred below the level of a spinal cord lesion. The time requize for recovery of the $\mathrm{H}$ reflex after vibration of muscle was similar to that after afferent tetanization of the muscle nerve at the same frequency as vibration was concluded that group 1a afferent volleys setgijpo by vibration of muscle depress monosynaptios activation of phasic motor neurones by a centrab mechanism.

Differentiation between tonic and phasic mechan isms in man by the reflex effects of muscle vibration may prove useful in the analysis of motor disorderso

The authors wish to express their gratitude to Sir Joh $\overrightarrow{\vec{F}}$ Eccles for his discussion of the experimental findings presented in this paper.

The project was made possible by grants from the National Health and Medical Research Council of Australia and the Post-Graduate Foundation in Medicine of the University of Sydney.

Ciba Company Pty. Ltd. kindly provided funds fo' equipment and supplies of Ciba $28,882-\mathrm{Ba}$. We are als grateful to Sandoz Australia Pty. Ltd., Merck Sharp and Dohme Pty. Ltd., and May and Baker (Australia) Pty소 Ltd., for their generous support.

The illustrations were prepared by Mr. John Toohey? of the Department of Medical Illustration, University of New South Wales.

\section{REFERENCES}

Bein, H. J., and Fehr, H.-U. (1962). Depression of muscle spindî activity-a new type of pharmacological action? Brit. 泡 Pharmacol., 19, 375-384. 
Bessou, P., and Laporte, Y. (1962). Responses from primary and secondary endings of the same neuromuscular spindle of the tenuissimus muscle of the cat. In Symposium on Muscle Receptors, edited by D. Barker, pp. 105-119. Hong Kong University Press.

Bianconi, R., and Van der Meulen, J. P. (1963). The Response to vibration of the end organs of mammalian muscle spindles. J. Neurophysiol., 26, 177-190.

Cooper, S. (1961). The responses of the primary and secondary endings of muscle spindles with intact motor innervation during applied stretch. Quart. J. exp. Physiol., 46, 389-398.

(1962). The behaviour of spindle receptors during muscle stretch. In Symposium on Muscle Receptors, edited by D. Barker, pp. 121-124. Hong Kong University Press.

Corrie, W. S., and Hardin, W. B. Jr. (1964). Post-tetanic potentiation of $\mathbf{H}$ reflex in normal man. Arch. Neurol. (Chic.), 11, 317-323.

Curtis, D. R., and Eccles, J. C. (1960). Synaptic action during and after repetitive stimulation. J. Physiol. (Lond.), 150, 374-398.

Denny-Brown, D. E., and Liddell, E. G. T. (1927). Observations on the motor twitch and on reflex inhibition of the tendon-jerk of M. supraspinatus. Ibid., 63, 70-80.

Eccles, J. C. (1964a). The excitatory responses of spinal neurones. In Progress in Brain Research, Vol. 12; Physiology of Spinal Neurons, edited by J. C. Eccles and J. P. Schadé, pp. 1-34. Elsevier, Amsterdam, London, and New York.

(1964b). Presynaptic inhibition in the spinal cord. Ibid., pp. 65-91.

- Eccles, R. M., and Lundberg, A. (1958). The action potentials of the alpha motoneurones supplying fast and slow muscles. J. Physiol. (Lond.), 142, 275-291.

- and Rall, W. (1951). Repetitive monosynaptic activation of motoneurones. Proc. roy. Soc. B, 138, 475-498.

Echlin, F., and Fessard, A. (1938). Synchronized impulse discharges from receptors in the deep tissues in response to a vibrating stimulus. J. Physiol. (Lond.), 93, 312-334.

Gassel, M. M., and Diamantopoulos, E. (1964). The effect of procaine nerve block on neuromuscular reflex regulation in man. An appraisal of the role of the fusimotor system. Brain, 87, 729. 742.

Granit, R., and Henatsch, H. D. (1956). Gamma control of dynamic properties of muscle spindles. J. Neurophysiol., 19, 356-366. , and Steg, G. (1956). Tonic and phasic ventral horn cells differentiated by post-tetanic potentiation in cat extensors. Acta physiol. scand., 37, 114-126.

Phillips, C. G., Skoglund, S., and Steg, G.(1957).Differentiation of tonic from phasic alpha ventral horn cells by stretch, pinna, and crossed extensor reflexes. J. Neurophysiol., 20, 470-481.
Hagbarth, K.-E. (1962). Post-tetanic potentiation of myotatic reflexes in man. J. Neurol. Neurosurg. Psychiat., 25, 1-10.

- , and Eklund, G. (1965). Motor effects of vibratory muscle stimuli in man. In Proceedings of the first Nobel Symposium, Stockholm, 1964. In the press.

Henatsch, H. D., Manni, E., and Dow, R. S. (1964). Effects of gamma loop interruption on cerebellar control of individual alpha motoneuron stretch reflexes. J. Neurophysiol., 27, 193209.

- - Wilson, J. H., and Dow, R. S. (1964). Linked and independent responses of tonic alpha and gamma hind-limb motoneurons to deep cerebellar stimulation. Ibid., 27, 172-192.

Jahn, S. Al Azharia (1963). Physiological properties of isolated neuromuscular spindles. Acta physiol. scand., 59, suppl. 213, pp. 67-68.

Lance, J. W. (1965). The mechanism of reflex irradiation. Proc. Aust. Ass. Neurol., 30, In the press.

- and De Gail, P. (1965). Spread of phasic muscle reflexes in normal and spastic subjects. J. Neurol. Neurosurg. Psychiat., 28, 328-334.

Languth, H. W., Teasdall, R. D., and Magladery, J. W. (1952). Electrophysiological studies of reflex activity in patients with ıesions of the nervous system. III. Motoneurone excitability following afferent nerve volleys in patients with rostrally adjacent spinal cord damage. Bull. Johns Hopk. Hosp., 91, 257-266.

Lundberg, A., and Winsbury, G. (1960). Selective adequate activation of large afferents from muscle spindles and Golgi tendon organs. Acta physiol. scand., 49, 155-164.

Matthews, P. B. C. (1963). The response of de-efferented muscle spindle receptors to stretching at different velocities. J. Physiol. (Lond.), 168, 660-678.

- (1964). Muscle spindles and their motor control. Physiol. Rev., 44, 219-288.

- and Rushworth, G. (1957a). The selective effect of procaine on the stretch reflex and tendon jerk of soleus muscle when applied to its nerve. J. Physiol. (Lond.), 135, 245-262.

- _ (1957b). The relative sensitivity of muscle nerve fibres to procaine. Ibid., 135, 263-269.

Murayama, S., and Smith, C. M. (1965). Rigidity of hind limbs of cats produced by occlusion of spinal cord blood supply. Neurology (Minneap.), 15, 565-577.

Rushworth, G., Lishman, W. A., Hughes, J. T., and Oppenheimer, D. R. (1961). Intense rigidity of the arms due to isolation of motoneurones by a spinal tumour. J. Neurol. Neurosurg. Psychiat., 24, 132-142. 